\title{
MID-SHAFT CLAVICLE FRACTURES;
}

Surgical Management

Dr. Kashif Khurshid Qureshi, Dr. Zulfiqar Ahmed, Dr. Imran Asif Bajwa, Dr. Saeed Ahmed, Dr. Hassan Moin

ABSTRACT... Objectives: To study the time to union and complications after open reduction and internal fixation of mid-shaft clavicle fractures. Design: Retrospective. Settings: Midlands Orthopedic/ Sports Injury Clinic, Bahawalpur. Study Period: 2003 to December 2012. Material and Methods: The medical record of the patients operated for mid-shaft clavicle fractures was searched to find out the time to union and occurrence of complications during this period. Results: The time to union was 4.6 months and there were two complications. A prominent implant had to be removed and one non-union required additional bone grafting procedure. Conclusions: This small series shows that the rate of complications is low and a larger study is needed to expand the indications for operative fixation of clavicle fracture safely.

Key words: Clavicle fractures, time to union, complications, reconstruction plate

Article Citation

Qureshi KK, Ahmed Z, Bajwa IA, Ahmed S, Moin H. Mid-shaft clavicle fractures; surgical management. Professional Med J 2013;20(6): 1006-1009.

\section{INTRODUCTION}

Clavicle fractures constitute about $4-10 \%$ of all fractures in the adults. About $35-45 \%$ of all shoulder girdle fractures are clavicle fractures ${ }^{1,2}$. Fractures of the mid-shaft account for approximately $80 \%$ of all clavicle fractures. Most of these injuries are the result of fall on the tip of the shoulder in contrast to the past concept that they were the result of fall on the outstretched hand. About $70 \%$ of clavicle fractures are the result of road traffic accidents and most occur in young adult males ${ }^{3,4,5}$. Fractures treated in broad arm sling heal with some shortening and bony prominence. The absolute indications for fixation of clavicle fracture fixation have been open fractures, polytrauma, associated neurovascular injury etc. However, certain fracture patterns have shown the need for early fixation. Recently, there has been a trend towards open reduction and internal fixation of the mid-shaft clavicular fractures ${ }^{6,7,8,9}$. Plate fixation provides rigid fixation, early mobilization and an earlier return to normal activity.

\section{MATERIALS AND METHODS}

The medical record of 12 patients operated at Midlands Orthopedic/Sports Injury Clinic, Bahawalpur between 2003 and December 2012 was retrospectively evaluated. All the patients were operated by a single surgeon. Selection criteria included fractures with tenting of skin, delayed union and desire to return to early use of upper limb. Ten out of 12 patients were males. Age ranged from 28-45 years. All had tried conservative management with broad arm sling or bone setting by local bone setters and were not happy. The surgical approach was superior and the patient had been positioned in modified beach chair position. The fixation device consisted of a reconstruction plate bent to conform to the contour of the clavicle. The plate was fixed in superior position. Interfragmentary fixation was done wherever possible. The patients were given a broad arm sling for the first week for comfort. On the first visit at one week post-operative physiotherapy was started. The stitches were removed at two weeks with a gradual return to activity. The patients were then followed up at 6 weekly interval post operative patients were allowed full use of the upper limb when radiological union was achieved.

\section{RESULTS}

The record of the clinic was searched for patients who had undergone fixation of the clavicle. Age range was 18-45 years. Ten out of twelve patients were males. 
Time to union and complications was assessed. Mean time to union was 4.5 months. Union was uneventful in 10 cases. One patient demanded the implant to be removed because of prominence. One patient had non-union and required bone grafting which then lead to union.

\section{DISCUSSION}

Fractures of the clavicle are common injuries with more than $75 \%$ of the fractures occurring in the midshaft of the clavicle ${ }^{10}$. Classically nearly all clavicle fractures have been treated conservatively by a broad arm sling or figure of eight bandage ${ }^{11}$. While broad arm sling showed better patient satisfaction, figure of eight was associated with many complications like axillay pressure sore and neurovascular compression ${ }^{12}$. Past studies had shown great satisfaction level with conservative management while open reduction was associated with higher rates of non-union ${ }^{13,14,15}$. However, $42 \%$ of people still had sequelae at 6 months in one study ${ }^{5}$. The same study suggests the exploration of alternative treatment options, including surgery, for certain clavicular fracture types.

McKee in his study of nonoperative treatment of displaced mid-clavicular shaft fractures detected significant residual deficits in shoulder strength and endurance. However, there was no control group that was treated surgically ${ }^{16}$. Only fractures for which there was absolute indication for fixation were internally fixed. Internal fixation for the rest of fractures was usually reserved for symptomatic non-union. There are certain fracture patterns for which early fixation are advisable to reduce the incidence of non-union, shoulder weakness and early fatigue ${ }^{17}$. These fracture patterns include mid-shaft fractures with greater than $2 \mathrm{~cm}$ of shortening or $1 \mathrm{~cm}$ displacement and unstable type II fractures of the distal end of clavicle ${ }^{18}$. The increasing role of surgical treatment in these frequent injuries has been outlined by McKee et $\mathrm{al}^{16}$. Significant shortening of the clavicle can alter the normal alignment of the shoulder girdle leading to dysfunction with high demand activities. Complete healing of the clavicle fracture takes about 3-6 months and then 15\% of the fractures might go into non-union. Early fixation has some advantages like early return to work and activities, less pain (fracture is stabilized), better chances of healing and less chances of malunion.

Potter and his colleagues evaluated 29 patients with closed, isolated and completely displaced midshaft clavicle fractures. The acute group included 15 fractures, treated with open reduction and internal compression plate fixation at a mean 0.6 months after fracture. The surgeon randomized 14 patients to the delayed group. All delayed group patients suffered from malunion or nonunion and underwent open reduction and compression plate fixation at a mean 66 months after fracture. There was no significant difference between groups with respect to gender, age, fracture of the dominant limb or fracture mechanism. In addition to the DASH and Constant Shoulder questionnaires, the investigators also conducted objective muscle strength and endurance tests using the Baltimore Therapeutic Equipment (BTE) Work Stimulator. Patients subjectively rated their satisfaction with the surgery on a scale of 0 (extreme dissatisfaction) to 10 (extreme satisfaction). Straight recovery was excellent in both groups in shoulder flexion, abduction, internal and external rotation. There was no statistical difference between the two groups. But, muscle endurance was much better in the acute fixation group and the difference was significant ${ }^{19}$.

In a prospective, randomized, multicenter study of more than 100 patients with displaced midshaft clavicle fractures, for example, the nonsurgical group healed at an average of 28 weeks, while the surgical group healed at an average of 16 weeks. These conclusions were reinforced by another prospective, observational study that also found higher nonunion rates in patients treated nonsurgically ${ }^{19}$.

Absolute indications for fixation are open fractures and 
neurovascular injury requiring exploration and repair. The strongest relative indication for surgery is a displaced clavicle with $2 \mathrm{~cm}$ or more of shortening. Other relative indications include multiple extremity involvement, floating shoulder, seizure disorders, and cosmesis. When considering surgery variables such as degree of displacement, shortening, and comminution should be carefully considered. Other variables include location of the injury (dominant or nondominant arm), the patient's activity level, status of the physes (open or closed), and the existence of other injuries. Incisional numbness and hardware irritation are real and not infrequent complications, as are scar concerns and the risk of infection. Studies support the risk of surgical complications.

In one study, 53 percent of surgical patients required plate removal. In another study of 125 patients who underwent ORIF, 12 percent needed reoperation, 4 percent had plate breakage, and 3.2 percent had loosening. Other complications included infection and frozen shoulders ${ }^{17,18,20,21,22}$.

\section{CONCLUSIONS}

In our small series we have seen that there are few complications and an earlier return to pre-injury status with no visible deformity. However, further comparative studies are needed to compare the results with other studies.

Copyright(C) 15 Aug, 2013.

\section{REFERENCES}

1. Nowak J, Mallmin H, Larsson S. The aetiology and epidemiology of clavicular fractures. A prospective study during a two-year period in Uppsala, Sweden. Injury. Jun 2000;31(5):353-8.

2. Nordqvist A, Petersson $\mathrm{C}$. The incidence of fractures of the clavicle. Clinical Orthopedics and Related Research 1994;300:127-32.

3. Stanley D, Trowbridge EA, Norris SH. The mechanism of clavicle fracture. Aclinical and biomechanical analysis. Journal of Bone and Joint Surgery-British
Volume 1988;70(3):461-4.

4. Pannike A. [Clavicular fractures--etiology, classification, diagnosis]. Hefte Unfallheilkd. 1982;160:43-54.

5. Robinson CM. Fractures of the clavicle in the adult. Journal of Bone and Joint Surgery-British Volume 1998;80(3):476-84.

6. Neer CS 2nd. Fractures of the distal third of the clavicle. Clin Orthop Relat Res 1968;58:43-50.

7. Robinson CM, Court-Brown CM, McQueen MM, Wakefield $A E$. Estimating the risk of nonunion following nonoperative treatment of a clavicular fracture. J Bone Joint Surg Am 2004;86:1359-65.

8. Rowe CR. An atlas of anatomy and treatment of midclavicular fractures. Clin Orthop Relat Res 1968;58:29-42.

9. Böstman 0, Manninen M, Pihlajamäki H. Complications of plate fixation in fresh displaced midclavicular fractures. J Trauma 1997;43:778-83./ Zenni EJ Jr, Krieg JK, Rosen MJ. Open reduction and internal fixation of clavicular fractures. J Bone Joint Surg Am 1981;63:147-51.

10. Crenshaw AH. Fractures of the shoulder girdle arm and forearm. In: Crenshaw AH, editor. Campbell's operative orthopaedics. 8th ed. St.Louis: Mosby Year book; 1992.p 989-1053.

11. Lester CW. The treatment of fractures of the clavicle. Ann Surg 1929;89:600-6.

12. Andersen K, Jensen PO, Lauritzen J. Treatment of clavicular fractures. Figure-of-eight bandage versus a simple sling. Acta Orthop Scand 1987;58:71-4.

13. Neer CS 2nd .Nonunion of the clavicle. J Am Med Assoc 1960;172:1006- 11./Eskola A, Vainionpää S, Myllynen P, Pätiälä $H$, Rokkanen P. Outcome of clavicular fracture in 89 patients. Arch Orthop Trauma Surg 1986;105:337-8.

14. Eskola A, Vainionpää S, Myllynen P, Pätiälä H, Rokkanen P. Outcome of clavicular fracture in $\mathbf{8 9}$ patients. Arch Orthop Trauma Surg 1986;105:337-8. 
15. Nordqvist A, Petersson CJ, Redlund-Johnell I. Midclavicle fractures in adults: end result study after conservative treatment. J Orthop Trauma 1998;12:572-6.

16. McKee MD, Pedersen EM, Jones C, et al: Deficits following nonoperative treatment of displaced midshaft clavicular fractures. J Bone Joint Surg Am 2006;88(1):35-40.

17. Hill JM, McGuire MH, Crosby LA. Closed treatment of displaced middle-third fractures of the clavicle gives poor results. Journal of Bone and Joint Surgery- British Volume 1997;79(4):537-9.

18. Webber MC, Haines JF. The treatment of lateral clavicle fractures. Injury 2000;31(3):175-9.

19. Potter J, McKee M, Schemitsch E. Immediate fixation vs. delayed reconstruction of displaced mid-shaft fractures of the clavicle. \#069. Presented at the
American Academy of Orthopaedic Surgeons 73rd Annual Meeting. March 22-26, 2006. Chicago.

20. Canadian Orthopaedic Trauma Society: Non operative treatment compared with plate fixation of displaced midshaft clavicular fractures. A multicenter, randomized clinical trial. JBone Joint Surg Am 2007;89(1):1-10.

21. Kulshrestha V, Roy T, Audige L: Operative versus nonoperative management of displaced midshaft clavicle fractures: A prospective cohort study. J Orthop Trauma 2011;25(1):31-38.

22. Potter JM, Jones C, Wild LM, Schemitsch EH, McKee MD: Does delay matter? The restoration of objectively measured shoulder strength and patientoriented outcome after immediate fixation versus delayed reconstruction of displaced midshaft fractures of the clavicle. J Shoulder Elbow Surg 2007;16(5):514-518. Epub Jul 12, 2007.

\section{AUTHOR(S):}

1. DR. KASHIF KHURSHID QURESHI

Assistant Professor

Department of Orthopedics

Quaid-e-Azam Medical College

Bahawalpur

2. DR. ZULFIQAR AHMED

Assistant Professor

Department of Orthopedics

Quaid-e-Azam Medical College

Bahawalpur

3. DR. IMRAN ASIF BAJWA

Orthopedic Resident

Department of Orthopedics

Quaid-e-Azam Medical College

Bahawalpur

4. Dr. Saeed Ahmed

Orthopedic Resident

Department of Orthopedics

Quaid-e-Azam Medical College

Bahawalpur
5. Dr. Hassan Moin

Orthopedic Resident

Department of Orthopedics

Quaid-e-Azam Medical College

Bahawalpur

Correspondence Address:

Dr. Kashif Khurshid Qureshi

Assistant Professor

Department of Orthopedics

Quaid-e-Azam Medical College

Bahawalpur

ortho_bwp06@yahoo.com 